\title{
Translation and Translation Criticism: Probing a Reciprocal Interrelation
}

\author{
VIRAJ Desai
}

\begin{abstract}
In the contemporary times, the horizons of knowledge are no more confined to a singular language but encompass a variety of knowledge systems; existing in the form of different literature(s), languages, and the cultures represented through them. "Knowledge has become plural now", notes A K Singh, and translation is increasingly perceived as an essential facilitator to access this multitude of knowledge(s). Translation, then, is shouldered with a two-fold responsibility of representing the source language/culture and of introducing new concepts and ideas to the target language readers. In that case, it becomes extremely important to explore and understand the crucial role played by Translation Criticism in the negotiations of literature(s), cultures, and ideas between two languages through translation. Going beyond the rather limiting ideas of evaluation and analysis, Translation Criticism attempts to discuss a translation essentially as a translation. Considering the above arguments, this paper sets out to explore the complex relationship of Translation, Translation Criticism, and the Translation Critic. Furthermore, it also attempts to fathom the ways in which Translation Criticism enriches translation by initiating a constructive discourse around it and vice versa. The paper also addresses various issues surrounding Translation Criticism especially in the context of Gujarati-English Translation. The last part of the paper consists of a holistic critique of a Gujarati short story in English translation. The short story selected for the critique is titled "Nā Kaums maam, Nā Kaums Bahār" by Saroj Pathak and translated into English as "Neither Within Parantheses Nor Without" by Rita Kothari.
\end{abstract}


Keywords: Translation Criticism, Translation Studies, Indian Literature in English Translation, Gujarati Literature in English Translation.

\section{Introduction}

In the twenty-first century, two extremely common yet juxtaposing views of translation have emerged: one is that of translation as an extremely casual and uncomplicated process that hardly requires any expertise and the other is of translation as an extremely crucial component in understanding the contemporary World; where culture(s), literature(s), belief systems and ideologies are travelling and conversing with each other rapidly; much more than at any point in the past.

The advent of online translation tools and other technological advances have created the perception of translation as a highly mechanical and uncomplicated process which can be carried out by anyone with knowledge of two languages, with the help of various online translation tools available. And thus, "the layman's view of translation is that it involves a simple process of linguistic transfer, whereby whatever is written in one language...can be transferred unproblematically into another language" (Bassnett: 02).

The spread of the first view, which is highly problematic, owes a lot to the fact that the scholarly discussions around translation have remained confined to a very small section of the academia. And the academia too was not attentive towards theorising translation as a discipline for a very long time. In translation, as in any other discipline, theory and practice go hand in hand. On one hand, where the practice of translation has been going on for hundreds of years in English and other European languages, the need to theorise translation and establish it as a discipline was not felt up until the late Twentieth century. In the Indian context, the practices of Bhashanar, Rupantar and Anuvad, which come closest to what 
the West calls 'translation', have existed for centuries now. In India, translation acts as a point of contact between the speakers of different languages and hence becomes a necessity for surviving the multilingual culture of India. Thus, for Indian scholars, translation somehow became "an everyday affair, hardly worth theorising" (Kothari 2006: 38). And even though there have been various commentaries on translation in the Indian languages through centuries, "no homogeneous or even systematic translation theory has emerged from these academic notes on translation" (ibid.).

When there have been no or very little efforts made towards systematically theorising translation in a language, it can obviously not be expected to have developed a practice of critiquing translations from/into that language. For example, in the case of Gujarati, there seems to be a general apathy towards critiquing translations and especially towards the texts translated from Gujarati into English. The absence of this critical practice leads to two major problems. First is that of the unavailability of the critiques of translations resulting into very poor or inappropriate translations being accepted as good translations.

Here, it is to be noted that the practice of reviewing translations is very well established in Gujarati. However, in such reviews, "the critics' focus is entirely on the source text" (Soni: 155) (Translation Mine) and hence, very little attention is paid towards various aspects of translation- both as a process and a product. This problem is to be found across the reviewing practices in various Indian and European languages and something that Translation Criticism intends to address.

The second problem is that of the lack of importance or credit attributed to the translator. In order to encourage the practice of translation furthermore, there is a dire need to problematize 
the role of the translator itself. Anisur Rahman calls translation "essentially an act of collaboration...with the translator playing the role of a prime collaborator" (52). Thus, the very practice of translation is centred on the translator who is constantly negotiating between not only two languages but also two cultures and literatures. It is the translator who carries the entirety of a text into an alien language and appropriates it in the linguistic, cultural, and literary realm of that language, all this while remaining loyal to the original text, its writer, and the source language.

Although being so crucial to the act of translation, translators are often neglected by both - the readers and the critics. A translation is rarely perceived as a product of the efforts of both - the author and the translator. Neglecting the collaborative nature of translation, the translator's name is seldom put next to the author's. In a scenario where the translator himself is so marginalised, the survival of the translation critic seems like a far-fetched dream. As the noted Gujarati translator/critic Raman Soni argues, "the translator will be less valued than the original writer and the critic criticizing that translation will be even less valued. In reality, we have imbibed such mentality" (155) (Translation Mine).

Thus, there is a rather urgent need to not only recognise the pivotal role of the translator in the process of translation but also to acknowledge the existence of a translation critic who is focused on producing comprehensive commentaries on translated texts by examining the act of translation from a holistic and objective point of view. The following parts of the paper would endeavor to discuss the issues surrounding Translation Criticism, especially in the context of GujaratiEnglish Translation and also present a specimen critique of a Gujarati short story in English translation. 


\section{Translation Criticism: A Few Perspectives}

Before initiating a discussion around the nature of Translation Criticism, it is important to address seemingly similar terms such as analysis, evaluation, assessment, and reviews of translations. The common factor among all these concepts is the inherent tendency of judging translations and thereby assigning some kind of a value to it. What are often lacking in such concepts are an in-depth scrutiny of a translation and the various aspects of it. Translation Criticism, on the other hand, focuses on probing a translated text by focusing on the elements, contexts, and process of translation from an objective perspective in order to produce comprehensive critiques of translated texts. Translation Criticism aims to go beyond the binary of either "trashing a translator's work on the basis of isolated errors" (Baker \& Saldanha: 237) or applauding a translation without any logical or substantial evidences in the text or judging a translation from a singular theoretical stance. It tends to strike a balance that can make the critiques of translation more holistic and credible. Apart from analyzing the translated text in the context of and in comparison with the source text, Translation Criticism should also aim at analyzing a translation as a text in its own right, fulfilling a certain purpose and performing a certain function in the target language, literature and culture at large.

One of the crucial roles that Translation Criticism plays is of providing comprehensive commentary about the nature and other aspects of translation which is scarcely available. While discussing the information available on translations, reviews of translations must be discussed. One of the major issues regarding the available reviews of translations is their indifference towards a translation as a translation. In Gujarati literature too, "the practice of examining translated works from the point of view of translation skills is rare", notes Sanjay 
Shripad Bhave (164) (Translation Mine). The primary task of a reviewer is to recognise the status of a translation to which majority of the reviewers are indifferent.

Another issue with the reviews of translations is that, "most reviews in dailies or periodicals are commissioned, either by publishers of the books or by the publications which carry the review. Apart from the pressure on the reviewer to promote the book, there are problems of space" (Sheriff: 28). It is evident that the reviewers are not always indifferent to translations but are often bound by such external factors. However, even when a reviewer of translation is not indifferent to the process and nature of translation, the comments on translation generally tend to be negative and downgrading. Most of the times, there seems to be a lacuna of an objective criteria of evaluation or criticism employed by such reviewers and hence, the reviews end up being limited to generating value judgments. Another issue entailing the objective criticism of translation is the selection of the corpora for such reviews. Majority of the times such reviews are based on randomly selected paragraphs or phrases which may or may not represent the translation adequately. As Lance Hewson rightly points out, "scholars point to weaknesses in translated texts by using ad-hoc and unsystematic criteria which give limited insight into short passages of a text, but which hardly serve to understand the general impact of translational choices" (02).

There are various approaches and theories of Translation Criticism that deal with one or the other aspects of translation. However, "given the large number of variables that any process of translation needs to contend with, no general theory of translation that takes into account all problems of linguistic and cultural transfer of meaning can be evolved", argues E. V. Ramakrishnan (167). It is evident that the lack of a single framework or theoretical approach to Translation Criticism is 
deeply rooted in the absence of a general theory of translation. Agreeing with Ramakrishnan, it can be argued that the entire proposition of propounding a general or single theory of translation seems a bit too ambitious and to an extent, impossible. The reason being that translation is not a singular phenomenon occurring in a void. Rather, it is dependent on a variety of factors such as language, literature, culture, society, history to name a few and has different participants attributing to its being at various levels such as an author, a translator, a reader, a reviewer, a translation critic, etc. Considering such a vast nature of translation, one single theory or framework of Translation Criticism that can deal with it seems impractical and even limiting. Each translated work, having its unique identity and characteristics, demands its own set of approaches of criticism pertaining to its peculiar aspects. There cannot be an ideal set of approaches to critique a particular translation. The set of approaches would depend on the criteria set in the critic's mind. For example, a cultural critique of a translation would obviously deal with a different set of approaches than those of a semantic critique. Whatever the tools and the criteria may be, it is extremely important for a critic to choose his/her set of approaches wisely as it not only lays a strong foundation to a critique but acts as a compass for a translation critic to navigate through the complex and intricate labyrinth of a translation, especially a literary translation.

\section{Gujarati-English Translation and Translation Criticism: A Specimen}

This section of the paper consists of a critique of the English translation of the short story titled "Nā kaums maam, nā kaums bahār" by noted Gujarati short story writer, Saroj Pathak, translated by Rita Kothari as "Neither Within Parentheses Nor Without". 
Before talking about the practice of Translation Criticism with reference to Gujarati-English translation, it is important to have a cursory look at some undercurrents of the contemporary translation practices in Gujarati. Gujarati has been enriched by a stupendous number of celebrated and key texts translated from English and the other European and Indian languages. However, this activity of translation has majorly been unidirectional, i.e. the number of texts translated from Gujarati into English is almost nonexistent in front of the number of texts that have come to Gujarati from English and other European languages via English. "The regret of this flow of translation being one-way would be there in our hearts. It is a reality that excellent works of Gujarati Literature have not reached other languages to the extent that they should have", opines Late Bhagwatikumar Sharma (02) (Translation Mine). However, not much has been done towards overcoming this regret or guilt. Undoubtedly, some of the greatest works of Gujarati literature are available in English translation today, such as Dhruv Bhatt's Aküpār translated by Vishal Bhadani, or K. M. Munshi's PāTan ni Prabhutā, Gujarāt no Nāth and Rājādhirāj translated by Rita Kothari and Abhijit Kothari, Joseph Macvan's āngaliyāt translated by Rita Kothari or Gowardhanram Tripathi's Saraswatichandra translated by Tridip Suhrud to just name a few among many other such works. However, even after such timely and much needed efforts, only a drop from the vast ocean of Gujarati literature has been able to reach English through translation. While it is indeed important to commend such efforts, keeping a check on the quality of such translations is equally important. As Himanshi Shelat has noted:

We are generally apathetic towards studying and scrutinising translations. The inclination towards the same is very less. Resultantly, we often tend to accept 
the amateur (translations) (Shelat 164) (Translation Mine).

Such apathy is further fuelled by the apprehension of not many translators coming up with Gujarati-English translations in future due to the fear of a strict scrutiny. However, Translation Criticism is pivotal to the survival of not only the practice of Gujarati-English translation but also to Gujarati language. For translations represent the source language and culture in another language and thus, it becomes extremely necessary to keep a check on such representations, especially in contemporary times when the number of English-Gujarati translations are significantly low in comparison to the vast pool of the works of Gujarati literature. And, with the possible increasing number of Gujarati-English translations in future, the role of Translation Criticism as a gatekeeper would become even more crucial in order to maintain a certain standard of quality in translation.

Coming back to the present critique, the first step of this critique shall be gathering and discussing all the primary and ancillary data about the text. The discussion of the primary data of a text is an important step as it clarifies the structure of the critique. Such a discussion of the primary data of both, the source and the target text, forms the first step of some coveted models/frameworks of Translation Criticism such as Lance Hewson's Model of Translation Criticism (2011) and Juliane House's Model of Translation Quality Assessment (1977, rev. 1997). In Hewson's model such primary survey and discussion is the first step of his six-step method of Translation Criticism whereas in House's model it constitutes certain parts of the 'Tenor' and the 'Mode'. Talking about the short-story under consideration, the source-text was first published in a collection of short-stories by Saroj Pathak titled Virat Tapakum, published in 1966 by Sahitya Sangam, Surat. Saroj 
Pathak (1929-1989) was an eminent post-modern short-story writer in Gujarati. The translation by Rita Kothari is published in a collection of Gujarati Short-Stories in English Translation titled, Speech and Silence: Literary Journeys by Gujarati Women, published in the year 2006. No other translation of the concerned short story has been published in any other language in the knowledge of the writer of this paper. Saroj Pathak was a celebrated novelist, short-story writer, and essayist of Gujarati Literature. Opining about Pathak's remarkability as a short-story writer, Rita Kothari opines that "Saroj Pathak experiments with the short story form and the possibilities of handling psychological complexity through it." (Kothari "Introduction", xiii) This characteristic style of Pathak's work comes across in the story under consideration in a brilliant manner. The story, although woven around a particular event, focuses more on the emotional and psychological universe of its protagonist, Shuchi. A significant portion of the story is written in a very conversational form of language and the other half is in the stream of consciousness. Thus, the treatment given to the subject in the story completely justifies the subject matter.

Talking about the narrative structure of the story, it is noteworthy that even though the majority of the narrative consists of conversational language in incomplete sentences, the overall structure of the narrative holds the subject very well. The translator, too, chooses to retain this rather conversational structure the narrative in order to bring the core of the original text in the translation. The story talks about Shuchi, a housewife living a happy and prosperous life with her husband and her four daughters. Shuchi comes across as a very loving and cheerful wife and mother, binding the entire household together with her love. Shuchi's husband, Divya, is used to hosting lots of guests every now and then, and Shuchi happily hosts all of them with a lot of enthusiasm on all 
occasions. However, her enthusiasm is replaced by sheer anger as she discovers about the probable visit of her ex-lover. Majority of the story's focus is on depicting Shuchi's anger on the surface and an unconscious eagerness to see him who remains unnamed throughout the story. The story ends with depicting how the resentment of him not visiting Shuchi remains unrealised even by her. In most parts, the translation is a literal one with sentences or structures modified only to suit the English language best.

On analyzing the text, one of the first things that a critic may notice is the translator's decision to retain certain phrases in Gujarati/Hindi and not translate them. Colloquial words such as chālo, pallu, pretbhojan, guvār, tamāśa a, etc. have been transliterated in the translation. Though these words help in retaining the authenticity of the translation; it can become difficult to read for the readers not acquainted with Gujarati/ Hindi. Such choices in translation are always debatable because they have both - pros and cons attached to them. However, a strong argument against such a decision can be that translation is essentially carried out for the readers who cannot read the original and such a choice can lead to a rather fragmented understanding of the text in translation. Though the translator's decision aids in retaining the cultural authenticity of the text, providing an explanation/ translation of such colloquial words in form of footnotes or in some other way would have contributed towards the effective transfer of meaning in translation. Following is another example of how the absence of the explanation of the transliterated colloquial words can hinder a non-native reader's comprehension of the text. For example, the following sentence:

Oh! āvo rameshbhā̄i, ā jarā chākho to, sūraṇanum rāītum! Bāphelā sūraṇano chhūmìdo karīne... ne emām mārā nāmanī rāī...śum tame ne! māro dimāg... 
This sentence has been translated as:

Oh! Come along Rameshbhai, taste this, Sooran nun Raitu! You boil the sooran and mash it...a little rye...what, oh no please! My mind...

Colloquial words/concepts such as 'Süran' (a type of yam frequently used for cooking in India) and 'rāītum' (a dish made of yogurt mixed with spices and vegetables) have not been explained. As a result, the reader gets digressed from understanding and appreciating the text completely. Another error of mistranslating a word becomes evident here where the Gujarati word 'rāì'; meaning 'mustard seeds', has been confused with 'rye' in translation which is a type of grain. Such negligence on the part of the translator completely distorts the meaning of the sentence.

The translation, however, succeeds to large extent in retaining the meanings and emotions conveyed not only through language but also by the structure of the narrative, especially the parts written in the stream of consciousness. One example can be the sentence stated below:

Hāsya-ānand nī divālo māmi taDa paDī. īmit, chūno, dhūlano kachro sumiar sajāvelā beThakakhanDa mām khari kharine verāvā maānDyā.

It has been translated as:

A crack in the wall of joy and laughter, Bricks, cement, dust spilled into the beautifully designed and decorated living room.

This sentence is very crucial to the story as the crack in the wall is symbolic of the turmoil created in Shuchi's mind upon knowing about her ex-lover's arrival. And the essence of the same has been beautifully captured in the translation. The 
following paragraph further establishes the merit of the translation under consideration:

Shuchi mahemāno ne ramūj mām pret kahetī ane tene jamāDavānī vātanā ThaThārāne 'pretbhojan' eTale āvā mahemāno māTe banatum khās bhojan kahetī. Pharī vātanā pravāhamām jhukī javā taiyār thayelī Shuchi ne hāth vaDe khemchato hoy tem potānā taraf vāline Divya e kahyu:

This paragraph has been translated as:

Shuchi jokingly referred to the guests as 'spirits', and the elaborate spread made for such guests was Pretbhojan in her words. Eager to merge with the stream of conversation once again, Shuchi was pulled back physically by Divya who told her:

These specimens stand as the testimony to the appropriate stylistic and vocabulary choices made by the translator in order to transfer the meaning of the text in an appropriate and befitting manner. However, the translator's decision of translating the word 'pret' as 'spirits' and transliterating 'pretbhojan' on the other hand, seems a little contradicting and puzzling.

In the end, it can be said that the translation by Rita Kothari conveys the meaning of the source text in the translation successfully to an extent. The overall impact of the source text gets adequately reflected in the translation as well. The translation successfully carries the meaning and emotions of the source text; mostly written in conversational language and fragmented or incomplete sentences. One outstanding instance establishing the merit of the translation is when the translator chooses to paraphrase a sentence in order to transfer the meaning properly rather than translating literally, which would have distorted the meaning completely in this case. The 
sentence is "āmbalīnām peTanām khāTām chhe, kah̄̄ chho mom machkoDato". Had this sentence been literally translated, the meaning would have been entirely lost in the process of translation. Thus, the translation by the translator, "Let him make a face" seems appropriate. Though simplified, it comes across as a befitting translation in this case. Another fact worth mentioning is that there is only one translation available of the text under consideration. Hence, this translation can act as a reference point for other translators attempting to translate this text in future. The translators should keep both the merits and demerits of the translation and eventually come up with a more appropriate translation while attempting to translate the same text. For one of the most crucial aims of Translation Criticism should be to establish a reciprocal interrelation with the practice of translation that enriches both these practices simultaneously.

\section{Conclusion}

In spite of the difference in the approaches that the various models or theories of Translation Criticism take; what lies at the core of all these theories/models of Translation Criticism is the aim to provide critiques of translations based on a comprehensive interpretation and analysis of both the source text and the target text. Thus, Translation Criticism does not confine itself to passing binary judgments about a translation which is generally the case with translation reviews. Instead, it focuses on providing all-encompassing, detailed and rather objective critiques of translations. Availability of such trustworthy and enlightening critiques of translations can act as guidelines for other translators attempting translations of the same or some other work. It can also help preventing future translators from committing some common and obvious errors pertaining to a particular text which ultimately can result in the availability of better translations - the ultimate aim of 
Translation Criticism. Hence, at the core of the Translation Criticism, lies the concern of the constant betterment of the translation and of the best possible transference of meaning from the source-text to the target-text. Translation is shouldered with the crucial responsibility of making not only a text but also an alien culture, language, and literature available to the readers. And Translation Criticism can play a pivotal role aiding the transference of the meaning of words and other extratextual elements such as culture, literature and language, disguised in the cloak of words.

\section{References}

Baker, Mona, \& Gabriela SAldanha. 2011. Routledge Encyclopedia of Translation Studies. London: Routledge.

BASSNETT, SUSAN. 2014. Translation. The New Critical Idiom. London \& New York: Routledge.

Bhave, SAnjay Shripad. 2003. Anuvad. In Bholabhai Patel, Ramesh Dave, Parul Kandarp Desai, and Sanjay Shripad Bhave, (eds.), Gujarati Sahityano Dasamo Daayko (The Tenth Decade of Gujarati Literature). Ahmedabad: Gujarati Sahitya Parishad.

Hewson, LanCE. 2011. An Approach to Translation Criticism: Emma and Madame Bovary in Translation. Amsterdam \& Philadelphia: John Benjamins Pub. Company.

Kothari, Rita. (ed.). 2006. Introduction. In Speech and Silence: Literary Journeys by Gujarati Women. New Delhi: Zubaan, an imprint of Kali for Women.

KotharI, RITA. 2006. Translating India: the Cultural Politics of

English.http://www.cambridge.org/core/product/identifier/9 788175968226/type/BOOK.

PATHAK, SAROJ. 1996. Nā kauṁs maam, nā kaums bahār. In VirāTa Tapakum. Surat: Sahitya Sangam. 
PATHAK, SAROJ. 2006. Neither Within Parantheses Nor Without. In Rita Kothari (trans.), Speech and Silence: Literary Journeys by Gujarati Women. New Delhi: Zubaan, an imprint of Kali for Women.

RAHMAN, ANISUR. 2019. In Translation: Positions and Paradigms. Hyderabad: Orient Blackswan.

RAMAKRISHNAN, E. V. 2017. Locating Indian Literature: Texts, Traditions, Translations. Hyderabad: Orient Blackswan.

Sharma, Bhagwatikumar. 2010. Anuvadno Marg Dwimargi Banvo Joie. Parab Online 4(12). 2-3.

SHELAT, HimANSHI. 2018. Anuvad-Samiksha: A Doll's House by Henrik Ibsen, Anuvad- Balvant Jani. In Raman Soni (ed.), Anuvad-Vichar ane Anuvad-Prakriya. Vadodara: Pratyaksh Prakashan.

SHERIFF, K. M. 2008. Reviewing Translations: Translator's Invisibility Revisited. Translation Today, 5 (1\&2). 26-31.

SONI, RAMAN. 2009. Anuvad Na Aakara Vivechan Ni Jarur. In Raman Soni (ed.), Anuvad: Siddhant Ane Samiksha (Articles on Translation: Theory, Processes, and Problems). New Delhi: Sahitya Akademi.

$* * *$

\section{Cite this Work:}

DESAI, VIRAJ. 2020. Translation and Translation Criticism: Probing a Reciprocal Interrelation. Translation Today, Vol. 14(2). 21-36. DOI:10.46623/tt/2020.14.2.ar2 